\title{
Pipe-concrete columns of buildings and their fire-resistance determination
}

\author{
Nikolay Ilyin ${ }^{1, *}$, Nadezhda Kondratyeva ${ }^{1}$, and Vasily Zaiko ${ }^{1}$ \\ ${ }^{1}$ Samara State Technical University, Academy of Architecture and Civil Engineering, \\ Molodogvardeyskaya St., 194, Samara, 443001, Russia
}

\begin{abstract}
The research recognizes the necessity of developing a new method of calculation of pipe-concrete columns fire-resistance. It is important for expending the area of their application in construction of buildings and structures; in unique structures as well. The authors apply a simplified mathematical description of the process of pipe-concrete columns resistance to the standard fire effect. This method helps to increase the accuracy of fire resistance level determination to expand these constructions use. If buildings materials are rationally combined, it is possible to produce reliable and sufficiently fireproof structures. Pipeconcrete columns which are, in fact, metal pipes filled with concrete can serve as an example of such structures. Nowadays, field tests are used to determine pipe-concrete constructions fire resistance. The authors introduce a methodology of theoretical determination of pipe-concrete columns fire resistance limit. The use of the proposed methodology makes it possible to reduce labor and economic costs while determining buildings resistance with the use of the pipe-concrete. It opens a possibility of pipeconcrete structures reasonable application in construction practice. The use of this new method allows us to determine pipe-concrete columns fire resistance without resorting to natural fire. It also increases the accuracy of statistical quality control and non-destructive tests. The calculations made in this study as well as previous tests conducted by other researches prove that there is no need for additional fire protection of pipe-concrete columns.
\end{abstract}

\section{Introduction}

The creation of new structures is based, first of all, on the provision of the required bearing capacity. The main role is given to the reliability of the future structure. The fire resistance of building structures is not, as a rule, a high-priority task, although it makes up a large part of the security of the entire building. With a rational combination of building materials it is possible to obtain reliable and sufficiently fire-resistant structures. Pipe-concrete columns which are, in facr, metal pipes filled with concrete can serve as an example of such structures.

\footnotetext{
* Corresponding author: kafvv@mail.ru
} 


\section{Materials and methods}

Pipe-concrete and reinforced concrete columns are similar in structure, therefore, it is necessary to proceed from existing methods for determining fire resistance of reinforced concrete columns.

The method for evaluating the fire resistance of the reinforced concrete column of the building by making an experiment with the impact of the test load under conditions of the standard exposure to heat was originally used (GOST 30247.1-94, Test methods for fire resistance, Load-bearing and enclosing structures (1996)).

The method for determining the pipe-concrete column fire resistance was presented by French researches. It consisted in determining the distribution of temperatures over the column cross section and the magnitude of its ultimate load-carrying capacity during the fire. Further, this value was compared with its test load [3].

The reinforced concrete column non-destructive test using the set of simple quality measures can be considered the most accurate method for determining fire resistance [4]. With the appearance of new methods for calculating fire resistance of such structures, fullscale tests are no longer necessary and there is the possibility of their justified application in construction. It is also recognized that labor and economic costs have reduced.

The essence of the developed method for determining the pipe-concrete column fireresistance is to place real limits of the pipe-concrete column fire resistance by nondestructive methods.

An undeniable achievement of the proposed method is the absence of the pipe-concrete column full-scale fire tests. In addition, labor intensity and economic costs are reduced. Technology capabilities increase and allow us to calculate the fire resistance of pipe concrete columns of various parameters with varying load rating. The method increases the accuracy of calculations and simplifies the mathematical apparatus to describe the process of the column resistance to the thermal power.

\section{Results}

To define the fire resistance according to the specified method researchers have to find the degree of the section reinforcement, pipe metal mass factor and the resistance time to the fire effect by the metal sheathing. They also calculate the critical load and rigidity of the pipe-concrete column, consider influence of its deflection on the bending moment of the longitudinal force, as well as calculate the duration of the concrete fire protection by the pipe metal.

The fire resistance rating of the pipe-concrete column is proposed to be determined using the analytical equation (1):

$$
F_{u r}=\frac{\pi \cdot d_{b}^{2} \cdot\left(1-J_{\sigma o}\right)^{2} \cdot\left(1-0,6 \cdot \alpha_{m t}\right) \cdot \gamma_{n}}{D_{b t}^{2} \cdot R_{b n}^{0,25}}+\tau_{i, f p l}
$$

where $d_{b}$ - diameter of the column concrete cross-section, $\mathrm{mm} ; \mathrm{J}_{\sigma \mathrm{o}}$ - intensity of force stresses in the column design section $\left(J_{\sigma 0} \leq 1\right) ; \alpha_{\mathrm{mt}}-$ degree of the column section reinforcement by the pipe metal $\left(\alpha_{\mathrm{mt}} \leq 1,66\right) ; \gamma_{\mathrm{n}}$ - coefficient of the importance level as intended (low level $\gamma_{\mathrm{n}}=0,8$; normal level $\gamma_{\mathrm{n}}=1,0$; higher level $\gamma_{\mathrm{n}}=1,2$ ); $\mathrm{D}_{\mathrm{bt}}-$ concrete thermal diffusion exponent, $\mathrm{mm}^{2} / \mathrm{min} ; \tau_{\mathrm{i}, \mathrm{pp}}-$ interval or the concrete fire protection by them pipe metal, min.; $\mathrm{R}_{\mathrm{bn}}$ - concrete specified compression resistance $\mathrm{MPa}$. (2):

The intensity of stresses in the column design section $\left(\mathrm{J}_{\sigma o} \leq 1\right)$ is found using equation 


$$
J_{\sigma o}=\frac{M_{\xi}}{M_{c c}}
$$

where $\mathrm{M}_{\xi}$ and $\mathrm{M}_{\mathrm{cc}}$ - the design longitudinal force bending moment in view of the column deflection and, accordingly, the bending moment characterizing the ultimate strength of the column, $k H \cdot m$.

The cross-sectional area of the pipe metal $\left(A_{m m}, \mathrm{~mm}^{2}\right)$ is calculated by formula (3):

$$
A_{m t}=\frac{\pi \cdot\left(d_{m t}^{2}-d_{b}^{2}\right)}{4}
$$

where $d_{m t}$ and $d_{b}$ - the outer diameter of the metal pipe and accordingly, the diameter of the column concrete section, $\mathrm{mm}$;

The degree of the column saturation by the pipe metal $\left(\alpha_{\mathrm{mt}}\right)$ is calculated by equation (4):

$$
\alpha_{m t}=\frac{A_{m t}}{A_{b}} \cdot \frac{R_{u, m t}}{R_{b n}}
$$

where $A_{m t}$ and $A_{b}$ - the cross-sectional area of the pipe metal and, respectively, the cross sectional area of the column concrete, $\mathrm{mm}^{2} ; R_{u, m t}$ and $R_{b n}-$ ultimate resistance of the pipe metal and, accordingly, concrete's standard resistance to the axial compression, MPa.

The reduced thickness of the pipe metal $\left(\Theta_{s r}, \mathrm{~mm}\right)$ is determined by formula (5):

$$
\Theta_{s r}=\frac{\delta_{m t} \cdot\left(d_{m t}-\delta_{m t}\right)}{d_{m t}}
$$

where $\delta_{m t}$ - the pipe metal thickness, $\mathrm{mm} ; d_{m t}$ - the outer diameter of the metal pipe, mm. The fire resistance time of the unfilled pipe metal $\left(\tau_{u, m t}\right)$ is determined by equation $(6)$ :

$$
\tau_{u, m t}=110 \cdot\left[\left(1-J_{\sigma o}\right)^{1 / 2}-0,5\right]+0,6 \cdot \Theta_{s r}
$$

where $J_{\sigma o}-$ the intensity of initial stresses from the test load in the column design section $\left(J_{\sigma o} \leq 1\right) ; \Theta_{s r}$ - the reduced thickness of the pipe metal, mm.

The interval of the concrete fire protection by the pipe metal $\left(\tau_{u, f p l}\right.$, min. $)$ is calculated by equation (7):

$$
\tau_{u, f p l}=m_{o} \cdot \tau_{u, m t}
$$

where $m_{o}$ - heating conditions index of the pipe metal $\left(m_{o}=1 / 3\right) ; \tau_{u, m t}$ - fire resistance time of the unfilled pipe metal, min.

Critical strength $\left(\mathrm{N}_{\mathrm{cr}}, k H\right)$ perceived by the pipe-concrete column is calculated by equation (8):

$$
N_{c r}=\frac{\pi^{2} \cdot R I G_{0}}{l_{0}^{2}}
$$

where $\mathrm{RIG}_{0}$ - the stiffness of the pipe-concrete column, $\mathrm{m} ; l_{0}-$ the design length of the column, $\mathrm{m} ; \pi=3,14$.

The stiffness of the pipe-concrete column $\left(\mathrm{RIG}_{0}\right)$ is determined according to SP (design and construction specifications) 266.1325800.2016, condition (9): 


$$
\mathrm{RIG}_{0}=\min \left\{\begin{array}{l}
k_{b} E_{b 1} I+k_{s} E_{p} I_{p} \\
k_{b} E_{b 1} I+\frac{l_{0}^{2}}{\pi^{2}} R_{p c} A_{p}
\end{array}\right.
$$

where $E_{s}$ and $E_{b 1}$ - the modulus of the reinforcement elasticity and, respectively, the modulus of the compressed concrete deformation, $\mathrm{MPa} ; I_{p}$ and $I-$ the moment of the reinforcement inertia and the concrete section with respect to its center of gravity, $\mathrm{mm}^{4} l_{0}-$ the design length of the column, $\mathrm{m} ; \pi=3,14 ; R_{p c}$ - standard resistance of the pipe metal under compression as a component of the pipe-concrete element; $k_{s}, k_{b}$-coefficients for calculating steel and concrete rigidity using formulas $(10,11)$ :

$$
\begin{aligned}
& k_{s}=0,7 \\
& k_{b}=\frac{0,15}{\varphi_{l}\left(0,3+\delta_{e}\right)}
\end{aligned}
$$

$\delta_{e}-$ the relative value of the longitudinal force eccentricity determined by equation (12):

$$
0,15 \leq \delta_{e}=\frac{e_{0}}{d_{m t}} \leq 1,5
$$

where $d_{m t}$ - the outer diameter of the metal pipe, $\mathrm{mm} ; e_{0}-$ eccentricity of the longitudinal force, $\mathrm{mm}$;

$$
R_{p c}=R_{y}-\frac{1}{4} R_{y}\left(1-\frac{7,5 e}{d_{m t}-2 \delta_{m t}}\right)
$$

The use of the mathematical description of the process of the loaded pipe-concrete column resistance to the standard fire test and the established polyparametric equation (1) the accuracy and efficiency of the design fire-resistance evaluation.

The above method for determining the pipe-concrete column fire resistance is exemplified by the design scheme (Figure 1), where the arrows show the direction of the standard fire high temperature $t_{s t}{ }^{\circ} \mathrm{C}$.

\section{Discussion}

Pipe-concrete columns have a number of advantages and a good fire resistance is not an exception. Filling the steel pipe with concrete increases the rigidity of the elements; the local stability of the pipe walls and significantly improves the bearing capacity and fire resistance. They are also corrosion resistant. The pipe in these structures functions as longitudinal and transverse reinforcement and also serves as a fixed formwork. The major asset of pipe-concrete columns is the enhanced bearing capacity due to the volume reduction of the concrete core, which allows reducing the size of the cross-section. The idea of using these columns is not without strong appeal due to their reliability. They do not immediately lose their bearing capacity on reaching the limit state, but can withstand imposed loads for quite some time.

Thus, it may be noted that it is advisable to use pipe-concrete columns in modern construction with a large volume of unique buildings and structures that require enhanced security conditions. When you use these constructions, it is necessary to know their real fire resistance. 
Pipe-concrete columns are known to have a higher fire resistance than metal ones. Fullscale tests showed that pipe-concrete columns can be used without additional fire protection in buildings not lower than the third degree of fire resistance.

a)

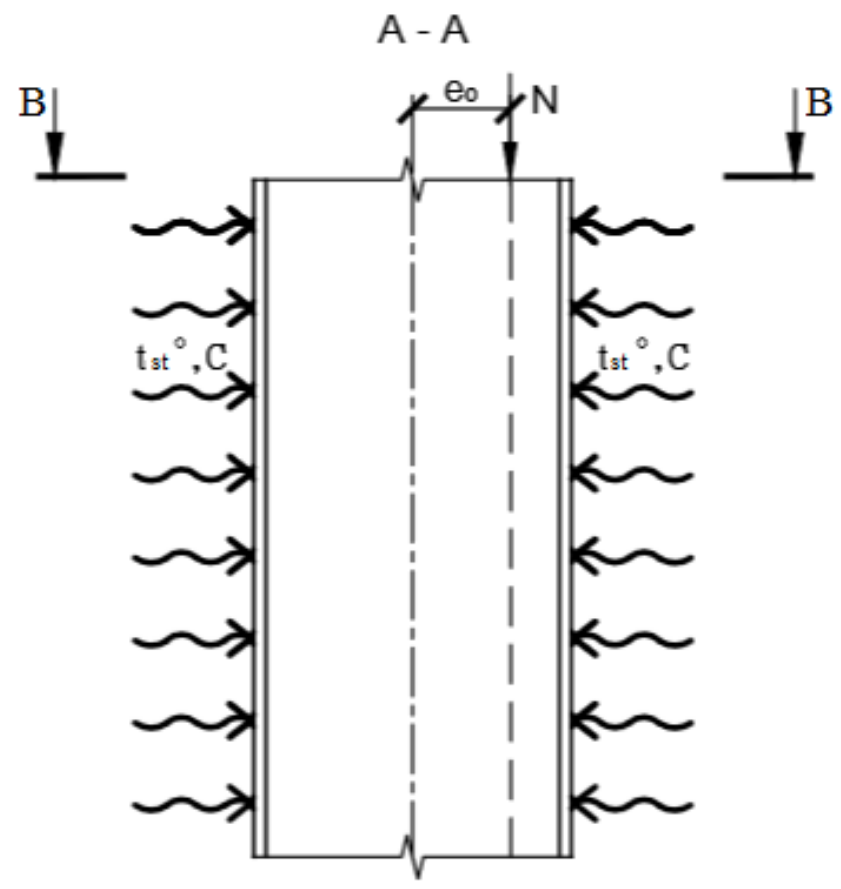

b)

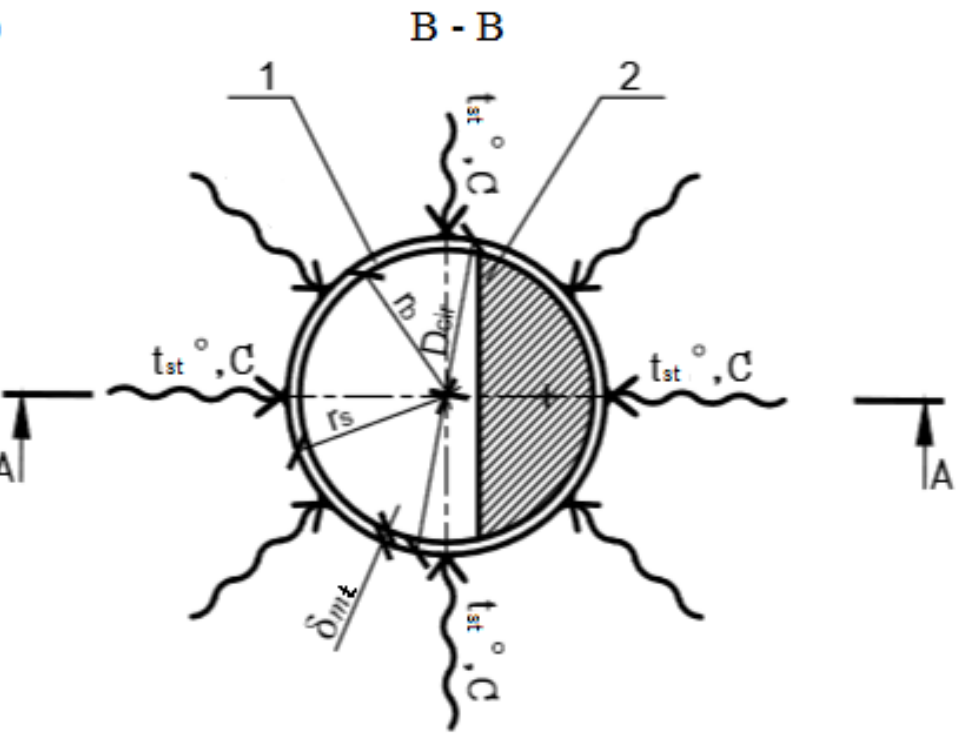

Fig. 1. Scheme of calculating the fire resistance of the pipe-concrete column: longitudinal section (a) and cross-section (b) with the following agreed notation: 1 - metal pipe; 2 - concrete; $\mathrm{N}$ longitudinal force, $\mathrm{kN} ; \mathrm{e}_{0}$ - longitudinal force eccentricity about the reduced section center of gravity, 
$\mathrm{mm} ; \mathrm{D}_{\text {cir }}-$ pipe-concrete column diameter, $\mathrm{mm} ; \mathrm{r}_{\mathrm{b}}, \mathrm{r}_{\mathrm{s}}-$ radii of the concrete section and metal pipe, $\mathrm{mm} ; \mathrm{t}_{s t},-$ temperature of the standard fire, ${ }^{\circ} \mathrm{C}$.

\section{Conclusions}

The quantitative evaluation of the design fire resistance of a pipe-concrete column is described by the analytical equation of seven variables and the calculation formula (1) is derived. The use of analytical dependencies for evaluating the pipe-concrete column fire resistance considerably reduces the time spent on thermotechnical and thermostability calculations.

The use of the simplified mathematical description of the loaded pipe-concrete column resistance to the standard fire action increases the design fire resistance accuracy. It can widen practical application of these structures.

\section{References}

1. I. I. Ovchinnikov, I. G. Ovchinnikov, G. V. Chesnokov, E. S. Mikhaldykin, Science St., 7, 4 (2015)

2. I. A. Duvanova, I. D. Salmanov, Const. of Un. Build. and Struc., 6 (2016)

3. B. Bartelemi, Z. H. Kryuppa, Fire resistance of building constructions (Moscow, Construction publishing house, 1985)

4. N. A. Ilyin, S. A. Butenko, S. V. Esmont, Patent $2281482 R U$ MPK G01N25/50 (2006)

5. Design and construction specifications 63.13330.2012, Concrete and reinforced concrete constructions, Fundumental principles, (2012)

6. Design and construction specifications 266.1325800.2016, Steel and reinforced concrete constructions, Design rules (2016) 